\title{
DESENVOLVIMENTO DE BIONEGÓCIOS E CONHECIMENTO TRADICIONAL: UMA ANÁLISE DE SUAS INFLUÊNCIAS NAS POPULAÇÕES TRADICIONAIS NO BRASIL
}

\author{
DEVELOPMENT BIOBUSINESS AND TRADITIONAL KNOWLEDGE: AN \\ ANALYSIS OF THEIR INFLUENCE IN TRADITIONAL POPULATIONS IN \\ BRAZIL
}

\author{
Clarissa Bueno Wandscheer ${ }^{1}$
}

\begin{abstract}
RESUMO
O presente artigo pretende abordar como o desenvolvimento dos bionegócios afeta as populações tradicionais no Brasil. Para isso o texto está estruturado em três partes principais: na primeira serão discutidos o conceito e a identificação das populações tradicionais, conhecimento tradicional e bionegócios; na segunda parte será apresentado a forma legal para o acesso ao conhecimento tradicional e os impactos no desenvolvimento de bionegócios, e; na última parte serão discutidos alguns casos de acesso ao conhecimento tradicional e repartição de benefícios e a difícil avaliação sobre a efetividade da repartição justa e equitativa de custos e benefícios em termos de bionegócios e conhecimento tradicionais.
\end{abstract}

Palavras-chave: Desenvolvimento. Bionegócios. Conhecimento tradicional. Populações tradicionais.

\begin{abstract}
This article aims to address the development of biobusiness affects traditional populations in Brazil. For this, the text is divided into three main parts: the first discussed the concept and the identification of traditional communities, traditional knowledge and biobusiness; the second part will be presented the legal form for access to traditional knowledge and the development impacts of biobusiness, and; in the latter part will discuss some cases of access to traditional knowledge and benefit sharing and the difficult assessment of the effectiveness of the fair and equitable sharing of costs and benefits in terms of biobusiness and traditional knowledge.
\end{abstract}

Keywords: Development. Biobusiness. Traditional knowledge. Traditional populations.

\footnotetext{
1 Universidade Positivo. Endereço: Rua Professor Pedro Viriato Parigot de Souza, 5300 - Campo Comprido, Curitiba - PR, 81280-330. Telefone: (41) 3317-3000. Possui doutorado em Direito Econômico e Socioambiental pela Pontifícia Universidade Católica do Paraná (2011), mestrado em Direito Econômico e Social pela Pontifícia Universidade Católica do Paraná (2003) e graduação em Direito pela Pontifícia Universidade Católica do Paraná (2001). Atualmente é professora doutora da Universidade Positivo e Faculdades da Indústria. Membro do Grupo de Pesquisa "Meio Ambiente: Sociedades Tradicionais e Sociedade Hegemônica" que visa estabelecer e consolidar a linha de pesquisa Meio Ambiente, Sociedades e Estado, que vem sendo desenvolvida no Programa de Pós-Graduação em Direito da Pontifícia Universidade Católica do Paraná, como parte integrante da área de concetração Direito Econômico e Socioambiental. clarissawand@gmail.com
} 


\section{Introdução}

Para situar a discussão pode-se destacar alguns pontos importantes como, de um lado, a Constituição Federal de 1988 proteger os direitos de propriedade intelectual nos termos do art. $5^{\circ}$, incisos XXVI, XXVII e XXIX. E, de outro, estabelecer que constituem o patrimônio cultural brasileiro os bens de natureza material e imaterial, incluindo as formas de expressão, os modos de criar, fazer e viver e as criações científicas, artísticas e tecnológicas, dos diferentes grupos formadores da sociedade brasileira, conforme artigo 216. Dentre as diversas práticas culturais que merecem proteção do Estado brasileiro, as das comunidades tradicionais, por força indireta da proteção cultural, assim como as indígenas pelo status constitucional conferido em 1988. Com efeito, é dever da União Federal a proteção dos bens de natureza material e imaterial dos índios em decorrência do artigo 231. A Medida Provisória (MP) 2186-16 de 23 de agosto de 2001, destinada a proteger os conhecimentos tradicionais associados ao patrimônio genético, determina que a proteção aos conhecimentos tradicionais não afetará, prejudicará ou limitará os direitos de propriedade intelectual. Também se incorporou ao ordenamento jurídico brasileiro uma série de normas de direito internacional diretamente relacionadas ao tema. É o caso da Convenção sobre a Diversidade Biológica, da Convenção 169 da OIT, da Declaração das Nações Unidas sobre os direitos dos povos indígenas, do Tratado Internacional sobre Recursos Fitogenéticos para a Alimentação e Agricultura, entre outros. Por fim, cumpre mencionar as discussões legislativas sobre o Projeto de Lei $\mathrm{n}^{\circ} 7735$ que pretende substituir a MP 2186-16, estabelecendo novas regras para a utilização do conhecimento tradicional associado à biodiversidade.

Dentro deste panorama, se pretende nesse artigo refletir somente alguns pontos relacionados a utilização de conhecimento tradicional e bionegócio. Para isso, se inicia com uma discussão sobre os conceitos e os entendimentos a respeito de conhecimento tradicional, populações e comunidades tradicionais e bionegócios. Em seguida é tratado de que forma a legislação nacional permite o acesso ao conhecimento tradicional associado e as perspectivas diante da possibilidade de alteração de regime jurídico, tendo em vista a discussão do Projeto de Lei $n^{\circ}$ 7.735. Este Projeto de Lei no 7735 foi aprovado na Câmara dos Deputados em 10 de fevereiro de 2015 e em 12 de fevereiro do mesmo ano, a Mesa da Câmara dos Deputados encaminhou o projeto para o Senado Federal, onde aguarda deliberação. E, por fim, serão apresentados alguns casos de acesso ao conhecimento tradicional associado à biodiversidade $\mathrm{e}$ as formas de repartição de benefícios adotada. 


\section{Padronizando conceitos: populações tradicionais, conhecimentos tradicionais e} bionegócios

É importante deixar claro que o conceito legal de conhecimento tradicional e das comunidades que os detêm não é o mesmo defendido pelos estudiosos do tema. Inicia-se, dessa forma, apresentando os contornos da definição de populações e/ou comunidades tradicionais para então se chegar ao que se entende por conhecimento tradicional.

Para Diegues e Arruda (2001) as populações ou as sociedades tradicionais podem ser identificadas como grupos humanos diferenciados sob o ponto de vista cultural, que reproduzem historicamente seu modo de vida, de forma mais ou menos isolada, com base na cooperação social e relações próprias com a natureza. Essas populações desenvolveram e desenvolvem modos particulares de existência, adaptados a nichos ecológicos específicos. Ou seja, essas comunidades se relacionam com a natureza de uma forma diferenciada. Normalmente, com métodos próprios de manejo da natureza.

Em 2001 foi editada a Medida Provisória 2.186-16 que regula o acesso à biodiversidade nacional e ao conhecimento tradicional, que será comentada a seguir, e apresentou a definição comunidade local (artigo 7, III) com sendo "grupo humano, incluindo remanescentes de comunidades de quilombos, distinto por suas condições culturais, que se organiza, tradicionalmente, por gerações sucessivas e costumes próprios, e que conserva suas instituições sociais e econômicas".

Mas em 2007 surge outra definição para as populações tradicionais que aparece no Decreto no. 6.040, de 2007, que institui a Política Nacional de Desenvolvimento Sustentável dos Povos e Comunidades Tradicionais. Por esse decreto os povos e comunidades tradicionais passam a ser identificados como os "grupos culturalmente diferenciados e que se reconhecem como tais, que possuem formas próprias de organização social, que ocupam e usam territórios e recursos naturais como condição para sua reprodução cultural, social, religiosa, ancestral e econômica, utilizando conhecimentos, inovações e práticas gerados e transmitidos pela tradição (artigo 3, I)”. O Projeto de Lei n 7.735 também apresenta uma proposta de definiç̧ão para comunidade tradicional em seu artigo $2^{\circ}$, IV comunidade tradicional - grupo culturalmente diferenciado, que se reconhece como tal, possui forma própria de organização social, e ocupa e usa territórios e recursos naturais como condição para a sua reprodução cultural, social, religiosa, ancestral e econômica, utilizando conhecimentos, inovações e 
práticas geradas e transmitidas pela tradição.

De um instrumento normativo a outro é possível observa uma profunda mudança na concepção dessas comunidades e/ou populações e/ou povos. A questão cultural é mantida, mas à ela é acrescida com destaque a utilização de seus territórios e dos recursos naturais, já que é a forma como essas populações os utilizam que as diferencia da forma de organização da sociedade envolvente. A autonomia de tais populações também é destaque, uma vez que está expresso no decreto o direito ao autorreconhecimento e o reconhecimento de que possuem formas próprias de organização social e também formas próprias de lidar com a natureza. E todo esse conhecimento é transmitido pela tradição, mesmo sem constar dos currículos das escolas tradicionais.

Importante ressaltar que esses direitos, ao autorreconhecimento e à autonomia, já constam de tratados internacionais como a Convenção 169 da Organização Internacional do Trabalho em seu artigo $1^{\circ}$ :

1.A presente convenção aplica-se:

a) aos povos tribais em países independentes, cujas condições sociais, culturais e econômicas os distingam de outros setores da coletividade nacional, e que estejam regidos, total ou parcialmente, por seus próprios costumes ou tradições ou por legislação especial;

b) aos povos em países independentes, considerados indígenas pelo fato de descenderem de populações que habitavam o país ou uma região geográfica pertencente ao país na época da conquista ou da colonização ou do estabelecimento das atuais fronteiras estatais e que, seja qual for sua situação jurídica, conservam todas as suas próprias instituições sociais, econômicas, culturais e políticas, ou parte delas.

2.A consciência de sua identidade indígena ou tribal deverá ser considerada como critério fundamental para determinar os grupos aos que se aplicam as disposições da presente Convenção.

$(\ldots)$.

A referida Convenção foi devidamente ratificada pelo Brasil pelo Decreto $5.051 / 2004$.

Para esse trabalho é necessário, também, esclarecer o que se entende por conhecimento tradicional. Dessa forma, apresentar-se-á uma versão doutrinária e uma legal sobre referido conhecimento tradicional. Esse conhecimento depende da forma como a

R. Bras. Planej. Desenv., Curitiba, v. 4, n. 2, p. 50-68, jul./dez. 2015 
comunidade e/ou população e/ou povo está organizado pois ele ocorre de forma coletiva, oral e intergeracional. Isso significa que o saber é difundido oralmente entre os integrantes da comunidade, desenvolvido de forma coletiva, porque é fruto do trabalho de vários de seus membros, e intergeracional porque a aplicação que se faz de determinado conhecimento passa pela interpretação e atualização das gerações presentes. Ainda, este conhecimento depende do ambiente em que vivem as populações tradicionais, pois estas possuem uma estrutura social de contato e respeito com a natureza, o que garante a sua utilização para a presente e para as futuras gerações. Cada comunidade/e ou população e/ou povo desenvolve técnicas de manejo e utilização dos recursos naturais de acordo com a disponibilidade destes nas áreas que ocupam, e em razão da abundância ou da escassez desenvolvem seus ritos e modos de vida. Por isso que as peculiaridades das comunidades e/ou populações e/ou povos estão relacionadas com seus territórios.

De outro lado tem-se o conceito legal trazido pela MP 2.186-16/2001, que em seu artigo $7^{\circ}$, II, determina que o: "conhecimento tradicional associado [constitui] informação ou prática individual ou coletiva de comunidade indígena ou de comunidade local, com valor real ou potencial, associada ao patrimônio genético".

É possível observar que há uma evidente redução do conceito de conhecimento tradicional, uma vez que se protege ou se reconhece como conhecimento tradicional somente o que pode ter um valor real ou potencial, e ainda, associado ao patrimônio genético. Legalmente somente uma parte do conhecimento tradicional é protegido como tal o restante deverá buscar guarida em outra parte do Direito.

Desse modo, é flagrante a utilização do patrimônio artístico e cultural desses povos e/ou comunidades e/ou populações, uma vez que não está qualificado como conhecimento tradicional e é necessário a intervenção de outros instrumentos jurídicos para a sua proteção. Se questiona a possibilidade da proteção por meio do sistema autoral e de proteção de marcas. No entanto, Baptista e Valle (2004) destacam algumas peculiaridades do caso indígena, por exemplo, a partir da análise de um grafismo:

(...) esse grafismo, diferentemente das obras em geral, apresenta algumas características peculiares: a) não tem, do ponto de vista de nosso sistema [sistema autoral], um autor ou conjunto de autores imediatamente identificáveis, pois sua "autoria" é produto de sucessivas recriações individuais ocorridas ao longo de gerações; e b) sua reprodução, apesar de poder comportar pequenas variações, segue padrões semelhantes transmitidos também ao longo de gerações, já que de forma

R. Bras. Planej. Desenv., Curitiba, v. 4, n. 2, p. 50-68, jul./dez. 2015 
geral serve como um meio de expressão visual que deve ser compreendido por aquele determinado grupo étnico.

Isso significa que, embora um artesão individualmente seja responsável por traçar uma determinada sílaba gráfica, usando para isso de seu talento e habilidade individual, a concepção artística e estética daquela obra não é fruto de sua criatividade individual, mas advém de uma criação coletiva, a qual não se limita, neste caso, à mera soma de contribuições individuais. (BAPTISTA; VALLE, 2004).

Ainda nesse tema é preciso tocar no que estabelece o projeto de lei (PL) 7.735, que está sendo discutido no Congresso Nacional para substituir a MP 2.186. O PL 7.735 em seu artigo $2^{\circ}$ apresenta o "conhecimento tradicional associado (como sendo) informação ou prática de povo indígena ou comunidade tradicional sobre as propriedades ou usos diretos ou indiretos associada ao patrimônio genético"; e inclui um conceito que não aparece na atual legislação que é o de conhecimento tradicional associado de origem não identificável e o conceitua como sendo o "conhecimento tradicional associado em que não há a possibilidade de vincular a sua origem a, pelo menos, um povo indígena ou comunidade tradicional". O que se identificaria como conhecimento tradicional difuso.

Por fim, é preciso tratar o que se entende por bionegócios. Pode-se apresentar bionegócio como sendo:

atividades com fins econômicos, desenvolvidas por empresas, que tenham como principal característica o uso intensivo - e, portanto, significativa dependência - de insumos da biodiversidade. (...) O que caracterizaria o bionegócio é o uso significativo que um elemento da biodiversidade tenha em suas operações. Assim, mesmo atividades econômicas que exijam menor elaboração, como por exemplo a comercialização in natura de frutos regionais, estariam abrigadas no conceito. (ARAÚJO FILHO, 2010)

Para Sousa (2014) os bionegócios são: “atividades econômicas voltadas à extração, beneficiamento e comercialização de insumos ou produtos que apresentem na sua composição recursos da biodiversidade que condicionem o valor agregado do produto, sejam eles na sua forma mais bruta ou tecnologicamente modificada".

Nenhuma dessas definições relaciona diretamente o envolvimento de conhecimentos tradicionais ou das comunidades e/ou populações tradicionais e povos indígenas. Mas não é possível excluir sua participação dessas atividades, uma vez que os produtos naturais extraídos das regiões habitadas por essas comunidades e/ou populações e/ou povos, R. Bras. Planej. Desenv., Curitiba, v. 4, n. 2, p. 50-68, jul./dez. 2015 
associados ou não ao seu conhecimento é um fator que agrega valor ao produto final.

Frickman e Vasconcellos (2010) defendem que os bionegócios são impulsionados pela base das cadeias produtivas da maioria dos bioprodutos que se inicia nas Reservas de Desenvolvimento Sustentável (RDS), Reservas de Extrativismo Sustentável (Resex), Florestas Nacionais (Flonas), Terras Indígenas e Unidades de Reforma Agrária Sustentável. (Apud Sousa, 2014).

Assim que para Sousa (2014):

O desenvolvimento deste mercado, em bases sustentáveis, com apoio científico e tecnológico induz a inclusão social das populações amazônicas, valorizando seus conhecimentos e inserindo a população num ciclo de atividade econômica tradicionalmente praticada, com aperfeiçoamentos tecnológicos capazes de agregar valor aos bioprodutos. As pesquisas científicas associadas apoiam estratégias de sustentabilidade social e ambiental, garantindo a conservação desses sistemas.

Vandana Shiva (2001) em seu livro "Biopirataria: a pilhagem da natureza e do conhecimento" já pregava a necessidade de se repensar uma forma de proteger a biodiversidade e os conhecimentos tradicionais da apropriação por interesses particulares. Em suas palavras: "precisamos mudar para um paradigma econômico alternativo que não reduza todo e qualquer valor a preços de mercado e toda e qualquer atividade humana ao comércio." (SHIVA, 2001).

Os anos passaram desde a edição de sua obra e se está justamente nesse ponto, ou seja, a legislação brasileira legitima a utilização da biodiversidade, associada ou não ao conhecimento tradicional, mas necessariamente deve haver um real ou potencial uso. Isso significa a possibilidade de utilização comercial do conhecimento e da biodiversidade.

\section{Metodologia}

A metodologia adotada envolve a pesquisa bibliográfica e documental, na medida em que há uma preocupação em identificar referências teóricas já públicas, principalmente, em livros jurídicos e artigos científicos da área. Para, a partir daí garantir a discussão e reflexão sobre novas propostas legislativas e os impactos na sociedade brasileira. 


\section{Resultados e discussões}

\subsection{Conhecimento tradicional associado: prática e perspectivas}

A atual legislação de acesso, a MP 2.186-16 prevê que o acesso ao conhecimento tradicional, segundo o artigo $7^{\circ}, \mathrm{V}$, é a "obtenção de informação sobre conhecimento ou prática individual ou coletiva, associada ao patrimônio genético, de comunidade indígena ou de comunidade local, para fins de pesquisa científica, desenvolvimento tecnológico ou bioprospecção, visando sua aplicação industrial ou de outra natureza".

O que se acessa é a informação, não se está transferindo uma propriedade material, mas um dado, ou seja, o acesso se dá a um patrimônio imaterial da comunidade indígena ou local. E isso muda toda a lógica do sistema legal. Não é a primeira vez que o sistema jurídico nacional se depara com a necessidade de proteger o patrimônio imaterial e o acesso ao conhecimento tradicional associado à biodiversidade gera discussões acaloradas em face das possibilidades de uso comercial de natureza.

Para Derani (2003 Apud Stefanello, 2013):

Emerge desta dissociação uma peculiaridade relativa ao poder de transmitir e transacionar sobre o direito de acesso. Como já dito, não se transaciona o bem, mas o seu conteúdo informativo. Poder-se-ia pensar que logicamente este conteúdo estaria sob o poder do detentor do bem, como imanente à propriedade ou como a ela acessório, na hipótese mais frágil. Ocorre que nenhuma destas formas tradicionais é pensada no caso do direito de acesso. Nem o conhecimento é um acessório da propriedade do bem, nem necessariamente o detentor do bem é detentor do conhecimento. Quem detém o bem não detém necessariamente o conhecimento, assim como as informações sobre um bem independem da relação de domínio do bem.

Em trabalho recente Stefanello (2013) entende que: “(...) todo recurso genético está contido num recurso biológico. Porém, após sua identificação e isolamento pelo acesso, ele pode existir independente do recurso biológico".

É importante destacar que essa informação só poderá ser utilizada com o devido consentimento da comunidade detentora de tal conhecimento e a anuência da União, que é a responsável por fiscalizar o procedimento de acesso através do Conselho de Gestão do Patrimônio Genético (CGEN), vinculado ao Ministério do Meio Ambiente.

R. Bras. Planej. Desenv., Curitiba, v. 4, n. 2, p. 50-68, jul./dez. 2015 
Importante destacar que o CGEN, órgão de caráter deliberativo e normativo criado pela MP no 2.186-16 no âmbito do Ministério do Meio Ambiente, é integrado por representantes de 19 órgãos e entidades da Administração Pública Federal (Ministério do Meio Ambiente; Ministério da Ciência e Tecnologia; Ministério da Saúde; Ministério da Justiça; Ministério da Agricultura, Pecuária e Abastecimento; Ministério da Defesa; Ministério da Cultura; Ministério das Relações Exteriores; Ministério do Desenvolvimento, Indústria e Comércio Exterior; IBAMA; Instituto de Pesquisa Jardim Botânico do Rio de Janeiro; CNPq; Instituto Nacional de Pesquisa da Amazônia; Instituto Evandro Chagas; Embrapa; Fundação Oswaldo Cruz, Funai, Instituto Nacional de Propriedade Industrial, Fundação Cultural Palmares) com direito a voto.

A legislação atual, MP 2.186-16, não dispõe claramente do termo consentimento, que vem previsto na Convenção da Diversidade Biológica (CDB), mas determina que a comunidade tem o direito de decidir sobre o uso de seu conhecimento tradicional. In verbis:

Art. $8^{\circ}$ Fica protegido por esta Medida Provisória o conhecimento tradicional das comunidades indígenas e das comunidades locais, associado ao patrimônio genético, contra a utilização e exploração ilícita e outras ações lesivas ou não autorizadas pelo Conselho de Gestão de que trata o art. 10, ou por instituição credenciada.

$\S 1^{\circ}$ O Estado reconhece o direito das comunidades indígenas e das comunidades locais para decidir sobre o uso de seus conhecimentos tradicionais associados ao patrimônio genético do País, nos termos desta Medida Provisória e do seu regulamento.(grifado)

Ainda que o referido artigo não esteja em conformidade com o que prevê a CDB as prerrogativas das comunidades tradicionais são maiores do que as perspectivas previstas no Projeto de Lei (PL) 7.735. O referido PL garante a proteção aos conhecimentos tradicionais contra a exploração ilícita. No entanto, em seu artigo $8^{\circ}, \S 1^{\circ}$ estabelece que as comunidades tradicionais têm o direito de participar da tomada de decisão. Um retrocesso em termos de autodeterminação das comunidades tradicionais. Para Nurit Bensusan (2015), ao comentar o consentimento prévio informado e suas perspectivas:

A figura do consentimento prévio informado é reconhecida mundialmente, inclusive em outras áreas como na medicina. Mas... como sabemos, o diabo está nos detalhes... A Medida Provisória (MP nº 2.186-16/2001) que regula esse tema, em vez

R. Bras. Planej. Desenv., Curitiba, v. 4, n. 2, p. 50-68, jul./dez. 2015 
de tratar a consulta e posterior decisão dos detentores do conhecimento tradicional sobre o acesso e uso de seu conhecimento como consentimento prévio informado, inventou um novo nome, anuência prévia. Com isso tirou dessa figura, o peso e o lastro que o consentimento prévio informado possui.

O PL n ${ }^{\circ} 7.735$, quando e se aprovado, deve substituir a Medida Provisória em vigor (2186-16) e regular o tema no Brasil. No texto atual, ainda passível de mudanças, a figura do consentimento prévio informado está de volta. Parece uma ótima notícia, mas não se deve esquecer: o diabo está nos detalhes! E lá está ele, outra vez...

A figura do consentimento prévio informado no PL é uma farsa, pois não é consentimento, não é prévio e nem é informado. Isso é cabalmente ilustrado por um detalhe, que fica claro quando examinamos um de seus dispositivos:

"O Estado reconhece o direito de povos indígenas, comunidades tradicionais e de agricultores tradicionais de participar da tomada de decisões, no âmbito nacional, sobre assuntos relacionados à conservação e ao uso sustentável de seus conhecimentos tradicionais associados ao patrimônio genético do País, nos termos desta Lei e do seu regulamento" (PL art $8^{\circ}, \S 1^{\circ}$ )

"Participar da tomada de decisões" não é decidir. Mesmo a Medida Provisória, sem a explícita menção à figura do consentimento prévio informado, dava aos povos indígenas e comunidades tradicionais mais poder de decisão sobre o uso de seus conhecimentos:

"O Estado reconhece o direito das comunidades indígenas e das comunidades locais para decidir sobre o uso de seus conhecimentos tradicionais associados ao patrimônio genético do País, nos termos desta Medida Provisória e do seu regulamento." (MP art $8^{\circ}, \S 1^{\circ}$ )

Também é importante lembrar que a regra vigente para o acesso prevê a repartição justa e equitativa dos benefícios derivados da exploração do patrimônio genético associado ao conhecimento tradicional. Mas não há clareza no que consistiria essa repartição, já que benefícios financeiros podem ser de várias formas: repasse de royalties, percentual de lucro líquido ou bruto obtido com a venda do produto final, pagamento por fase de pesquisa ou desenvolvimento, cobrança de taxas por acesso ou retirada de material genético associado ao conhecimento tradicional, oferecimento de bolsas de estudo ou cursos de capacitação para membros da comunidade, etc.

No entanto, pelo PL 7735, apesar de mencionar inúmeras vezes o termo repartição justa e equitativa, pouco esclarece como isso será garantido. Ou seja, fica a depender de regulamentos que deverão ser elaborados e fiscalizados pela União, por meio do CGEN, a 
regular repartição justa e equitativa dos benefícios oriundos da pesquisa.

A seguir o que dispõe o PL:

Art. 18. Os benefícios resultantes da exploração econômica de produto acabado oriundo de acesso ao patrimônio genético ou ao conhecimento tradicional associado, ainda que produzido fora do País, no qual o componente do patrimônio genético ou do conhecimento tradicional associado seja um dos elementos principais de agregação de valor ao produto, serão repartidos, de forma justa e equitativa, em conformidade ao que estabelece esta Lei.

$\S 1^{\mathrm{o}}$ Estará sujeito à repartição de benefícios exclusivamente o fabricante do produto acabado, independentemente de quem tenha realizado o acesso anteriormente.

$\S 2^{\circ}$ Os fabricantes de produtos intermediários e desenvolvedores de processos oriundos de acesso ao patrimônio genético ou ao conhecimento tradicional associado ao longo da cadeia produtiva estarão isentos da obrigação de repartição de benefícios.(grifado).

É preciso refletir sobre o que significa o produto acabado. Será o produto final pronto para a comercialização? Ou ainda, o produto final da pesquisa, mesmo que não seja dada uma destinação em escala comercial? E se o produto acabado levar anos para a sua elaboração, não haverá repartição de benefícios pelo acesso do conhecimento tradicional? No próprio artigo está prevista a não repartição de benefícios na parte de pesquisa, isso significa que o produto desenvolvido pode ser ótimo e curar até alguma forma de câncer, mas se for incompatível com a produção em escala ou a produção em escala não compensar economicamente, haverá produto final, mas não fabricante de produto acabado por falta de interesse mercadológico.

$\mathrm{Na}$ atual regulamentação MP 2.186-16, o conhecimento tradicional já é refém dos interesses econômicos, como mencionado no tópico anterior, uma vez que só é protegido o conhecimento tradicional com valor real ou potencial, associada ao patrimônio genético. E na perspectiva apresentada pelo PL 7.735 a exploração das populações e comunidades tradicionais se torna ainda maior, já que o acesso ocorrerá, mas o benefício pode não aparecer.

Se observa que cada vez mais há um afastamento da legislação nacional em face da CDB, segundo Santilli (2004):

(...) Quando a atividade envolve conhecimentos, inovações e práticas de povos

R. Bras. Planej. Desenv., Curitiba, v. 4, n. 2, p. 50-68, jul./dez. 2015 
indígenas e populações tradicionais, a CDB estabelece a necessidade de que sua aplicação se dê mediante a aprovação e a participação de seus detentores e a repartição dos benefícios com os mesmos. Ou seja, o objetivo fundamental da CDB é equilibrar as relações entre os países detentores da biodiversidade (países do Sul, em desenvolvimento) e os países detentores da biotecnologia (países do Norte, desenvolvidos). A matéria-prima da biotecnologia - a biodiversidade - está nos países em desenvolvimento, e o domínio sobre a biotecnologia e sobre as patentes sobre produtos ou processos biotecnológicos está nos países desenvolvidos.

Pela atual legislação o acesso depende do consentimento prévio das comunidades envolvidas, no caso de conhecimento tradicional, e para que o produto desenvolvido possa ser patenteado, ou seja, registrado no Instituto Nacional de Propriedade Intelectual (INPI), é preciso cumprir as condicionantes da Resolução $n^{0} 134$ do INPI e da Resolução $n^{0} 32$ do CGEN.

As resoluções entraram em vigor em 02 de janeiro de 2007, estabelecendo que o requerente de pedido de patente de invenção ou processo resultante de acesso a componente do patrimônio genético, envolvendo ou não conhecimento tradicional, realizado desde 30 de junho de 2000, deverá declarar ao INPI que cumpriu as determinações da Medida Provisória, informando o número e a data da autorização de acesso correspondente, além da origem do material genético e do conhecimento tradicional, se for o caso. Ou seja, deverá comprovar que há a anuência da população ou comunidade tradicional e a anuência da União, que fiscalizou o procedimento de acesso por meio do CGEN.

Para Stefanello (2013): "A obrigatoriedade de informar a origem do material genético contribui no combate à biopirataria. Além disso, entendemos ser acertada a medida articulada entre o CGEN e o INPI, que, em consonância de interesses, publicaram resoluções praticamente idênticas, mas cada um no âmbito de sua competência".

O que significa um mínimo de proteção para a utilização irregular do conhecimento tradicional. E, ainda, há uma diversidade de órgãos públicos responsáveis pela fiscalização e aplicação das disposições da MP 2.186-16 e seu regulamento. Segundo Stefanello (2013, p.82) esses órgãos seriam: “os agentes públicos do Ibama (no território continental brasileiro), do Comando da Marinha (águas de jurisdição brasileira e plataforma continental) e do Ministério da Defesa, na medida de suas competências, os quais podem atuar de ofício ou mediante representação de qualquer pessoa”. E ainda há a possibilidade dessa competência 
"ser delegada aos órgãos ambientais estaduais e municipais integrantes do Sistema Nacional do Meio Ambiente."

No PL 7.735 há a possibilidade de extinguir os processos administrativos em curso, iniciados por descumprimento de qualquer das normas previstas na MP 2.186-16. O procedimento administrativo está previsto no Decreto 5.459 de 07 de junho de 2005 e tem dentre as sanções aplicáveis, isolada ou cumulativamente, às pessoas físicas ou jurídicas (artigo 10): advertência; multa; apreensão das amostras de componentes do patrimônio genético e dos instrumentos utilizados na sua coleta ou no processamento ou dos produtos obtidos a partir de informação sobre conhecimento tradicional associado; apreensão dos produtos derivados de amostra de componente do patrimônio genético ou do conhecimento tradicional associado; suspensão da venda do produto derivado de amostra de componente do patrimônio genético ou do conhecimento tradicional associado e sua apreensão; embargo da atividade; interdição parcial ou total do estabelecimento, atividade ou empreendimento; suspensão de registro, patente, licença ou autorização; cancelamento de registro, patente, licença ou autorização; perda ou restrição de incentivo e benefício físcal concedidos pelo governo; perda ou suspensão da participação em linha de financiamento em estabelecimento oficial de crédito; intervenção no estabelecimento; e proibição de contratar com a administração pública, por período de até cinco anos.

E no artigo 40 do PL 7.735 consta que:

Art. 40. Deverá regularizar-se nos termos desta Lei, no prazo de um ano, contado da data de sua entrada em vigor, o usuário que, entre 30 de junho de 2000 e a data de entrada em vigor desta Lei, realizou as seguintes atividades em desacordo com a legislação em vigor à época:

I - acesso a patrimônio genético ou a conhecimento tradicional associado;

II - acesso e exploração econômica de produto oriundo do acesso a patrimônio genético ou a conhecimento tradicional associado;

III - remessa ao exterior de amostra de patrimônio genético; ou

IV - divulgação, transmissão ou retransmissão de dados ou informações que integram ou constituem conhecimento tradicional associado.

$\S 1$ o A regularização de que trata o caput está condicionada a assinatura de Termo de Compromisso.

$\S 20 \mathrm{Na}$ hipótese de acesso ao patrimônio genético ou conhecimento tradicional associado unicamente para fins de pesquisa científica, o usuário estará

R. Bras. Planej. Desenv., Curitiba, v. 4, n. 2, p. 50-68, jul./dez. 2015 
dispensado de firmar o Termo de Compromisso, regularizando-se por meio de cadastro ou autorização da atividade, conforme o caso.

$\S 30 \mathrm{O}$ cadastro e a autorização de que trata o $\S 2^{\circ}$ extingue a exigibilidade das sanções administrativas previstas na Medida Provisória no 2.186-16, de 2001, e especificadas nos arts. 15 e 20 do Decreto $n^{0}$ 5.459, de 7 de junho de 2005, desde que a infração tenha sido cometida até o dia anterior à data de entrada em vigor desta Lei.

Ou seja, haverá uma anistia dos procedimentos de acesso ao conhecimento tradicional associado ao patrimônio genético realizados de maneira irregular se houver a transformação em lei do referido PL. Uma vez que consta expressamente a extinção da exigibilidade das sanções administrativas previstas tanto pela MP 2.186-16 quanto pelo Decreto $5.459 / 2005$.

Por fim, é importante destacar que tanto a atual legislação como o PL em discussão no Congresso Nacional contrariam o que dispõe o Protocolo de Nagoya sobre Acesso a Recursos Genéticos e a Repartição Justa e Equitativa dos Benefícios Advindos de sua Utilização (ABS). Esse Protocolo é um acordo complementar à Convenção sobre Diversidade Biológica (CDB) da qual o Brasil é signatário.

O Brasil participou da discussão do texto do Protocolo de Nagoya e assinou, mas não cumpriu o prazo de ratificação, pois o Congresso Nacional não apreciou o texto e editou decreto legislativo confirmando a validade do documento em território nacional.

O objetivo desse instrumento internacional é a repartição justa e equitativa dos benefícios advindos da utilização de recursos genéticos, inclusive por meio do acesso adequado a recursos genéticos e da transferência adequada de tecnologias relevantes, considerando-se todos os direitos sobre tais recursos e tecnologias, e por meio do financiamento adequado, assim contribuindo para a conservação da diversidade biológica e para o uso sustentável de seus componentes, conforme artigo $1^{\circ}$. Também está previsto o respeito às leis consuetudinárias, protocolos e procedimentos comunitários habituais das comunidades indígenas e locais, conforme aplicável, com respeito aos conhecimentos tradicionais associados a recursos genéticos (artigo 12, item 1). E determina que cada Parte, ou seja, Estado associado, tome as medidas necessárias para assegurar que os conhecimentos tradicionais só possam ser acessados mediante a consentimento prévio fundamentado ou aprovação prévia e envolvimento dessas comunidades indígenas e locais, e que sejam 
estabelecidos termos mutuamente acordados (artigo 7).

O acesso ao conhecimento tradicional associado ao patrimônio genético para utilização em bionegócios não é tarefa fácil. E mesmo com alguns anos de aplicação da CDB, infelizmente sem a Protocolo adicional de Nagoya, e da MP 2.186-16 é possível, ainda, esperar retrocessos se o PL7.735 realmente virar lei.

\subsection{Casos de acesso ao conhecimento tradicional e repartição de benefícios: difícil avaliar a efetividade da repartição justa e equitativa}

Nesta parte o objetivo é apresentar alguns casos de acesso ao conhecimento tradicional associado à biodiversidade, ou seja, com potencial de bionegócio e as formas adotadas para a repartição de benefícios.

O primeiro caso, talvez o que tenha sido de maior impacto midiático, é o caso "Veras-Ervas", em Belém do Pará. Nessa situação as erveiras do mercado "Ver-o-Peso", em Belém do Pará denunciaram na Comissão de Bioética da Ordem dos Advogados do Brasil no Pará (OAB-PA) que a empresa de cosméticos Natura havia acessado conhecimento tradicional associado à manipulação dos recursos florestais não madeireiros que contêm essências aromáticas, especificamente priprioca, breu branco e cumaru. (SILVA, 2012).

A empresa de cosméticos alegou que o conhecimento das erveiras era conhecimento difuso, sem fonte determinada e, por isso, seria discutível a remuneração referente ao acesso de tais conhecimentos. A empresa se utilizou de entrevistas realizadas com as erveiras, mulheres que manipulavam óleos vegetais e essências aromáticas, mediante um pagamento simbólico, referente à concessão de direito de imagem, uma vez que foram feitos registros audiovisuais.

Neste caso também houve a intervenção do Ministério Público Estadual e Federal (4 ${ }^{\mathrm{a}}$ Câmara) para que a situação fosse resolvida. Com isso a empresa reconheceu a utilização de conhecimentos das erveiras e se comprometeu a realizar um contrato de repartição de benefícios.

Esse caso inaugura a participação das comunidades tradicionais nos Contratos de Utilização do Patrimônio Genético e Repartição de Benefícios (CURB). De forma, que a alegação de conhecimento difuso não dispensa a necessidade de repartição de benefícios, tendo em vista que houve acesso ao conhecimento tradicional.

Outro caso de acesso ocorreu na Reserva de Desenvolvimento Sustentável Iratapuru,

R. Bras. Planej. Desenv., Curitiba, v. 4, n. 2, p. 50-68, jul./dez. 2015 
em Laranjal do Jarí no Estado do Amapá. Em termos jurídicos é importante destacar que o Estado do Amapá possui legislação regulando a participação dos povos indígenas e comunidades locais na proteção e controle sobre o acesso à biodiversidade (Lei $\mathrm{n}^{\circ} 388$, de 10 de dezembro de 1997).

Os casos de acesso e utilização de recursos genéticos que ocorreram no Estado do Amapá se deram por meio de contratos de repartição de benefícios (CURB), sem necessidade de haver contencioso judicial. O que nos mostra a relevância da regulamentação estadual.

No Estado do Amapá já há um histórico de contratos e mobilização das comunidades, como se pode verificar no caso envolvendo a Cooperativa Mista dos Produtores e Extrativistas do Rio Iratapuru (COMARU) e a Natura, empresa de cosméticos, o que nos mostra que há influência da legislação estadual pertinente, pois, com as restrições e sanções previstas para a exploração econômica de produtos oriundos da floresta, ações passam a ser direcionadas, de modo preventivo. O primeiro contrato ocorreu em 2004, no qual se previa o financiamento da certificação de manejo florestal Forest Stewardship Council (FSC) por parte da empresa. (SILVA, 2012).

No tocante à repartição de benefícios constatou-se em resumo público de certificação da COMARU (2004), que teve o objetivo de avaliar a sustentabilidade ecológica, econômica e social do manejo florestal da cooperativa, que a comunidade vivia em situação precária. No entanto, em contato com representante da COMARU, a comunidade se apresentou satisfeita com a repartição de benefícios, tanto é que os contratos foram renovados até 2010.

(...) Além dos valores pagos em relação ao acesso a recurso genético, os benefícios não-monetários são distribuídos por meio de projetos encaminhados ao "Fundo Natura" e que muitos já foram executados, como capacitação da cooperativa, financiamento de acesso à educação de nível superior para os filhos dos cooperados, melhoria na infraestrutura da comunidade, como saneamento básico, etc. (SILVA, 2012).

Por fim, o caso da Cooperativa dos Pequenos Produtores Agroextrativistas de Esperantinópolis (COOPAESP), no Maranhão e, também, a Natura empresa de Cosméticos S.A. Segundo pesquisas de Silva (2012) em 2007 o Ministério Público Federal interviu para a reformulação do Contratos de Utilização do Patrimônio Genético e Repartição de Benefícios (CURB) entre a Natura e as Quebradeiras de Coco e houve uma satisfação das comunidades

R. Bras. Planej. Desenv., Curitiba, v. 4, n. 2, p. 50-68, jul./dez. 2015 
beneficiadas com o acesso e a repartição de benefícios.

O recurso genético acessado é a farinha do mesocarpo de babaçu. Em 2011, a Natura realizou acesso ao conhecimento tradicional associado ao babaçu junto à COOPAESP, tendo obtido seu consentimento para tanto e negociado o pagamento de repartição justa e equitativa dos benefícios decorrentes desse acesso, devidamente registrado no CGEN.

Em contato com representante da ASSEMA, por e-mail, foi informado que as quebradeiras de coco babaçú, dos Estados do Maranhão, Pará e Tocantins, foram beneficiadas com a repartição de benefícios pelos recursos aportados ao "Fundo Babaçu”, financiado pela empresa Natura pelo acesso ao patrimônio genético e CTA. (SILVA, 2012).

Esses são alguns casos de acesso em que houve contratos de repartição de benefícios, em sua grande maioria, os recursos foram repassados a fundos e redistribuídos para projetos nas respectivas comunidades. Importante, destacar que a repartição de benefícios não está adstrita ao repasse de recursos financeiros para os detentores do conhecimento tradicional, poderia ser através de parcerias produtivas, capacitação e treinamento, transferência de tecnologia, etc.

Todos os casos são recentes e o Brasil é um país propício para o desenvolvimento de atividades relacionadas com aos bionegócios e aos conhecimentos tradicionais. Só a experiência poderá demonstrar se estamos no caminho correto. Um bom indicativo seria a aplicação de convenções internacionais que se preocupam com o tema como a Convenção da Diversidade Biológica (CDB) e o Protocolo de Nagoya.

\section{Considerações Finais}

Desse modo, as populações e as comunidades tradicionais se caracterizam pela forma como se relacionam em grupo (tradições e costumes) e pela forma diferenciada como se relacionam com a natureza. Essa relação é essencialmente diferente da que é promovida pela sociedade envolvente, ou seja, a sociedade de tipo europeia ocidental.

Assim, a forma de produção de conhecimento é diferente, ou seja, o conhecimento é produzido coletivamente e coletivamente é reinterpretado e atualizado e adaptado as condições ambientais (variabilidade de espécies e ecossistemas).

É reconhecido à essas comunidades o direito ao seu autorreconhecimento e

R. Bras. Planej. Desenv., Curitiba, v. 4, n. 2, p. 50-68, jul./dez. 2015 
autonomia em seus territórios, isso abrange também a utilização da biodiversidade, de seus conhecimentos e o desenvolvimento de atividades que os envolvam, que em maior ou menor medida se relacionam com bionegócios.

As concepções de bionegócios apresentadas defendem o desenvolvimento em bases sustentáveis e porque não com bases em princípios sociais diferenciados e de um outro relacionamento com natureza. Ou seja, da inter-relação das comunidades e/ou populações tradicionais com o meio ambiente.

Essa perspectiva admite a exploração econômica dos conhecimentos tradicionais associados à biodiversidade, mas é necessário que outros conhecimentos, ainda não valorados pelo mercado, também possam ser protegidos juridicamente. Infelizmente, não é o que está previsto na legislação em vigor nem no Projeto de Lei já aprovado na Câmara dos Deputados e em discussão no Senado Federal.

No entanto, como observado no trabalho, a exploração econômica será sobre o patrimônio imaterial da comunidade e/ou população tradicional. E, atualmente, a autorização para utilização de tal patrimônio depende da anuência da comunidade detentora do conhecimento. Infelizmente, pelo PL 7.735 isso pode mudar. E a mudança não beneficia o detentor do conhecimento, mas sim os interesses econômicos relacionados com a exploração do meio ambiente, uma vez que determina a necessidade de participar do processo de decisão, mas não com direito de negar o acesso. Fica claro a vulnerabilidade das comunidades e populações tradicionais nos eventuais contratos de bionegócios.

Outro ponto polêmico tratado é a questão da repartição dos benefícios decorrentes de bionegócios. Uma vez que nem a atual legislação e nem o PL 7.735 são claros de que forma deverá ser realizado. O que poderá acabar em prejuízo das comunidades e /ou populações detentoras de conhecimento tradicional, conforme observado nos estudos de caso apresentados.

Ainda há um longo caminho jurídico a ser precorrido para garantir a proteção dos direitos coletivos dessas comunidades, de seus saberes e também de que forma, se assim o desejarem, esses direitos e conhecimentos poderão ser utilizados pelo mercado, ou seja, poderão ser transformados em bionegócios. 


\section{REFERÊNCIAS}

ARAÚJO FILHO, Guajarino de. Iniciativas em bionegócios e o programa pappesubvenção no Estado do Amazonas. Revista T\&C Amazônia, Ano VIII, n. 19, 2010.

BAPTISTA, Fernando M.; VALLE, Raul Silva Telles do. Os povos indígenas frente ao direito autoral e de imagem. São Paulo: Instituto Socioambiental, 2004.

BENSUSAN, Nurit. O diabo está nos detalhes... sempre... . Disponível em: http://www.socioambiental.org/pt-br/blog/blog-do-ppds/o-diabo-esta-nos-detalhes-sempre , Publicado: 08jan2015. Acesso em 13jan2015.

DERANI, Cristiane. Tutela Jurídica da Apropriação do Meio Ambiente e as Três Dimensões da Propriedade. HILÉIA - Revista de Direito Ambiental da Amazônia. Manaus, Universidade do Estado do Amazonas, Ano 1, no 1, 2003, p.70-.

SANTILLI, Juliana. Conhecimentos Tradicionais Associados à Biodiversidade: elementos para a construção de um regime jurídico sui generis de proteção. In: PLATIAU, Ana Flávia Barros. VARELLA, Marcelo Dias (orgs). Diversidade biológica e conhecimentos tradicionais. Belo Horizonte: Editora Del Rey, 2004, p.341-369.

SOUSA, Kleber A. A dinâmica da inovação em bionegócios no Estado do Amazonas. XXIV Seminário Nacional de Parque Tecnológicos e Incubadoras de Empresas. 22 a 26 de setembro de 2014. Belém/Pará/Brasil. 25p.

SHIVA, Vandana. Biopirataria: a pilhagem da natureza e do conhecimento. Tradução de Laura Cardellini Barbosa de Oliveira; prefácio de Hugh Lacey e Marcos Barbosa de Oliveira. Petrópolis: Vozes, 2001.

SILVA, Liana A. L, da. Conservação da Etnobiodiversidade à luz do ecologismo dos pobres: repartição equitativa de benefícios e práticas de comércio justo envolvendo povos amazônicos. In: MORATO LEITE, José Rubens; PERALTA, Carlos E. ; MORAES, Kamila Guimarães de. Anais da I Jornada Latino-Americana de Direito e Meio Ambiente Desafios para a conservação e uso sustentável da biodiversidade Brasil-Costa Rica . GPDA/ UFSC - Grupo de Pesquisa Direito Ambiental na Sociedade de Risco da Universidade Federal de Santa Catarina : Florianópolis/SC, novembro / 2012. P.272-291.

STEFANELlo, Alaim G. F. A proteção dos conhecimentos tradicionais no contexto dos direitos da sociobiodiversidade e dos direitos de propriedade intelectual. 2013. 259p. Tese de Doutorado - Pontifícia Universidade Católica do Paraná. Curitiba, 28/02/2013. Meio eletrônico - arquivo pdf.

Recebimento dos originais: 23/07/2015

Aceitação para publicação: 03/11/2015

R. Bras. Planej. Desenv., Curitiba, v. 4, n. 2, p. 50-68, jul./dez. 2015 